\title{
Manajemen Mitigasi Bencana pada Satuan Pendidikan Anak Usia Dini Untuk Pengurangan Risiko bencana Gempa Bumi dan Tsunami
}

\author{
${ }^{1 *}$ N. Nuraeni, ${ }^{1}$ M. Mujiburrahman, ${ }^{2}$ Rudi Hariawan \\ ${ }^{1}$ Prodi Bimbingan dan Konseling, FIPP, UNDIKMA Mataram, Jl. Pemuda No. 59A, Mataram, \\ Indonesia 83125 \\ 2Prodi Administras Pendidikan, FIPP, UNDIKMA Mataram, Jl. Pemuda No. 59A, Mataram, Indonesia \\ 83125) \\ *Corresponding Author e-mail: nuraenifip@gmail.com \\ Received: February 2020; Revised: March 2020; Published: March 2020

\begin{abstract}
Abstrak
Artikel ini bertujuan untuk memeberikan deskripsi tentang (1) Penangan manajemen bencana gempa bumi dan tsunami yang baik, dan (2) mitigasi bencana melaui pendidikan anak dini dengan menggunakan pendekatan pembelajaran model PURINA. Analisis data menggunakan studi pustaka yang telah tersedia dari berbagai literature cetak dan online. Hasil studi menyimpulkan bahwa; (1) manajemen bencana yang baik dapat dilakukan dengan tiga tahap, yaitu; tahap planning pra-bencana, dimaksudkan untuk meningkatkan kesiap-siagaan aturan, alat, fisik dan mental masyarakat terdampak; tahap implementation saat peristiwa terjadi, dimaksudkan untuk melakukan penyelamatan sesuai dengan standar operasional yang ditetapkan; dan tahap recovery pasca-bencana, dimaksudkan untuk melakukan pemulihan fisik dan mental masyarakat terdampak; (2) Penguatan manajemen bencana melaui pendidikan sejak dini dalam bentuk penerapan kurikulum pembelajaran kebencanaan di tingkat satuan PAUD.
\end{abstract}

Kata Kunci: Manajemen mitigasi, Model PURINA, Pendidikan anak usia dini

\section{Disaster Mitigation Management in Early Childhood Education Units for Disaster and Earthquake Disaster Risk Reduction}

\begin{abstract}
This article aims to provide a description of (1) Good management of earthquake and tsunami disasters, and (2) disaster mitigation through early childhood education using the PURINA model learning approach. Data analysis using literature studies that have been available from various printed and online literature. The study results concluded that; (1) good disaster management can be done in three stages, namely; pre-disaster planning stage, intended to improve the preparedness of the rules, tools, physical and mental impact of the affected community; implementation phase when the event occurs, intended to rescue in accordance with established operational standards; and the post-disaster recovery stage, intended to carry out physical and mental recovery of the affected community; and (2) Strengthening disaster management through early education in the form of implementing disaster learning curriculum at the level of early childhood education units.
\end{abstract}

Keywords: Mitigation management, PURINA Model, Early childhood education program

How to Cite: Nuraeni, N., Mujiburrahman, M., \& Hariawan, R. (2020). Manajemen Mitigasi Bencana pada Satuan Pendidikan Anak Usia Dini untuk Pengurangan Risiko bencana Gempa Bumi dan Tsunami. Jurnal Penelitian dan Pengkajian Ilmu Pendidikan: e-Saintika, 4(1), 68-79. doi:https://doi.org/10.36312/e-saintika.v4i1.200 


\section{PENDAHULUAN}

Indonesia sebagai daerah yang berada di wilayah rawan bencana sudah sepatutnya melakukan mitigasi bencana secara baik. Manajemen penanganan bencana dan pengaruhnya pada pengurangan risiko yang ditimbulkannya. Gempa bumi secara pola mekanisme adalah salah satu bencana alam yang dalam siklus tertentu akan terus berulang kemabli, ketika akumulasi energy tabrakan maksimum berada pada suatu titik lapisan bumi sudah tak sanggup menahan tumpukan energy yang kemudian energy tersebut akhirnya akan dilepas dalam bentuk guncangan gempa bumi (literasipublik.com)

Percepatan pelepasan gelombang energi seismik sesaat itulah yang menimbulkan gempa bumi dan berpotensi tsunami, mengakibatkan berbagai dampak kerusakan bangunan, tanah longsor, atau dapat mengakibatkan pergerakan tanah (liquefaction) yang dahsyat. Besarnya dampak gempa bumi terhadap kerusakan bangunan bergantung pada beberapa hal diantaranya; skala gempa, mekanisme sumber, jarak epicentre, kualitas bangunan dan jenis lapisan tanah. Gempa bumi tidak hanya mengakibatkan kerusakan dalam berbagai aspek fisik, akan tetapi menelan korban jiwa dan trauma yang berkepanjangan bagi masyarakat terdampak gempa (Literasipublik.com). Trauma ini hampir dirasakan bagi sebagian besar masyarakat dan tidak terkecuali anak-anak usia pra-sekolah, karena itupula membutuhkan penangan psikologis yang tepat dari para ahli, agar anak lebih cepat pulih darib traumanya.

Mengenal istilah mitigasi asal katanya dari Bahasa Latin, yaitu mitis (jinak) dan agare (melakukan). Singkatnya, mitigasi dilakukan untuk menjinakkan sesuatu dimana dalam pembahasan ini berarti bencana. Oleh karena itu, serangkaian tindakan yang dilakukan secara sistematis untuk mengurungi risiko dan dampak bencana. Mitigasi bencana menjadi bagian dari tahap awal penanggulangan bencana (sebelum bencana) (wikipedia.org)

Letak Indonesia secara geologis berada pada pertemuan tiga lempeng utama dunia yaitu Lempeng Eurasia, Lempeng Pasifik, dan Lempeng Indo-Australia itu sendiri. Karena itu pula, Indonesia mendapat julukan sebgai negara ring of fire atau lingkaran Api Pasifik. Kedua hal tersebut menjadi salah satu faktor Indonesia sering mengalami bencana alam. Bencana dapat diartikan sebagai peristiwa yang dapat mengancam dan mengganggu kelangsungan hidup masyarakat seperti kehilangan nyawa dan harta benda.

Definisi bencana yang termuat dalam Undang-Undang Nomor 24 Tahun 2007 tentang Penanggulangan Bencana pada Pasal 1 poin 1, disebutkan bahwa "bencana adalah peristiwa atau rangkaian peristiwa yang mengancam dan mengganggu kehidupan dan penghidupan masyarakat yang disebabkan baik oleh faktor alam dan atau non alam, maupun faktor manusia", sehingga tidak hanya menimbulkan korban jiwa manusia, tetapi juga dapat mengakibatkan kerusakan fisik bangunan, lingkungan alam, kerugian harta benda, ekonomi, dan dampak psikologis yang berkepanjangan (Nurjanah, 2012; Sonjaya, 2020 ).

Pada gambar 1 sebaran gempa bumi lombok tahun 2018 lalu. Zulfakriza yang dikutif Sodikin (2018) pada tahun 1963, 1976 dan 1979 sebaran gempa bumi terjadi di sekitaran wialayah Bali dan Lombok. Secara posisi terlihat bahwa sebaran gempagempa terjadi berada di bagian Utara Bali dan bagian Barat Lombok. Sedangkan untuk wilayah bagian Utara Lombok cederung tidak mengalami gempa dengan magnitudo yang signifikan. Mekanisme kejadian gempa yang terjadi pada 2018 
hampir memiliki pola yang sama dengan gempa yang pernah terjadi pada tahun 1963, 1976, dan 1979. Pola mekanisme gempa buminya adalah sesar naik. Pola mekanisme ini memberikan pemahaman bahwa gempa-gempa tersebut dipicu oleh aktivitas sesar naik yang berada wilayah bagian Utara Bali dan Lombok. Posisi gempa bumi Lombok tahun 2018 berbeda dengan posisi gempa bumi di tahun 1963, 1976 dan 1979. Akan tetapi tidak menutup kemungkinan bahwa kejadian gempa pada tahun 1963, 1976, dan 1979 dapat berulang kembali. Tentu tidak ada seorangpun mengharapkan kejadian gempa gumi pada tahun 1963, 1976 dan 1979 terulang kembali di masa mendatang.

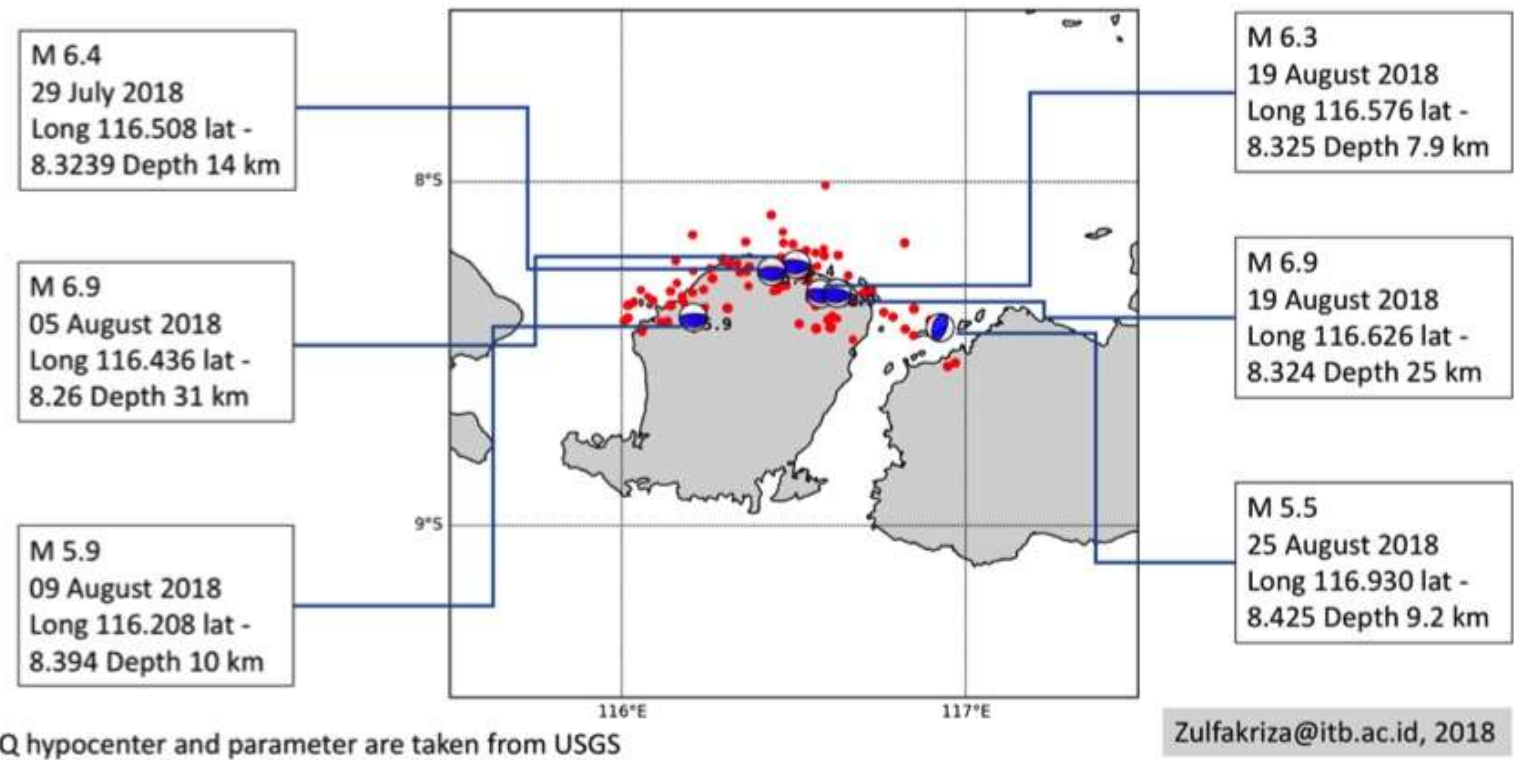

Gambar 1. Sebaran Gempa Bumi Lombok 2018 (Zulfakriza, 2018; Sodikin, 2018).

Jenis-jenis bencana dapat dikelompokkan dalam tiga kelompok jenis bencana, yaitu: (1) bencana alam adalah peristiwa akibat faktor geologis (pergerakan lempeng bumi), klimatologi (kondisi cuaca/iklim), dan ekstra-terrestrial (benda luar angkasa); (2) bencana non-alam adalah peristiwa akibat dari wabah penyakit, gagal teknologi, epidemi, dan gagal modernisasi; dan (3) Bencana sosial adalah peristiwa akibat konflik antar masyarakat, terorisme, dan sebagainya.

McCaffrey \& Nabelek dalam makalahnya yang berjudul Earthquake, Gravity, and The Origin of the Bali An Example of a Nascent Continental Fold-and-Thrust Belt memaparkan bahwa tidak kurang dari tujuh kejadian gempa dengan magnitudo yang relatif besar sejak tahun 1963 di wilayah Bali dan Lombok. Tujuh gempa bumi yang dimaksud yaitu; 2 gempa pada tanggal 18 dan 22 Mei tahun 1963, 1 gempa pada tanggal 14 Juli 1976, sedangkan di tahun 1979 terjadi tiga kali gempa dengan magnitudo yang signifikan yaitu pada $30 \mathrm{Mei}, 20$ Oktober dan 17 Desember 1979 (McCaffrey \& Nabelek, 1987). Badan Nasional Penanggulangan Bencana (BNPB) juga mencatat setidaknya antara tahun 2002-2009 terdapat 14 peristiwa bencana terjadi di wlayah Indonesia. Gempa bumi sebagai peristiwa encana yang paling sering terjadi, kemudian bencana tsunami, dan erupsi gunung berapi. Data-data ini menginformasikan bahwa bencana alam seperti gempa bumi merupakan peristiwa atau kejadian yang memiliki siklus tertentu dan akan terus terulang di masa mendatang.

Pada tanggal 29 Juli 2018 pukul 06.47 WIB terjadi bencana alam berupa gempa bumi bermagnitudo 6,4 Skala Richter (SR) mengguncang wilayah Lombok 
sekitarnya, pulau Sumbawa bagian barat dan Bali (Surat Kabar Kedaulatan Rakyat, Juli 2018). Seminggu kemudian yaitu pada tanggal 5 Agustus 2018 pukul 18.46 WIB gempa bumi susulan yang lebih dahsyat terjadi dengan magnitudo 7 SR menimpa kawasan Lombok Utara, Nusa Tenggara Barat dan berpotensi Tsunami (detik.com, Agustus 2018). Sejak terjadinya gempa pertama ditetapkanlah masa tanggap darurat bencana oleh Badan Nasional Penanggulangan Bencana (BNPB) sampai hari Sabtu, 25 Agustus 2018 (Tribunnews.com, 11 Agustus 2018). Berdasarkan data BNPB per-13 agustus 2018 yang 90\% sekolah di Lombok Utara mengalami berdasarkan data yang ditayangkan oleh CNN Indonesia bersumber dari Sekretariat Nasional Pendidikan Aman Bencana (SNPAB) khusus lombok utara 471 orang meninggal, 23.098 rumah hancur, 169 satuan pendidikan mengalami kerusakan, 112 masjid roboh, sebanyak 1.117 ruang kelas dan 407 ruangan pendukung rusak berat, sedangkan 215 ruang kelas mengalami rusak sedang dan ringan (Mujiburrahman \& Masjudin, 2019)

BNPB merilis data per-tanggal 10 September 2018, gempa tersebut telah memakan korban jiwa 564 orang, 1.584 orang mengalami luka dan pengungsi 445.343 orang. Terdapat 214 kerusakan pada infrastruktur, 1.194 unit sekolah mengalami kerusakan, 321 fasilitas kesehatan rusak, rumah ibadah rusak seperti masjid sejumlah 630 unit, 461 Mushalla, 1 Gereja di Mataram, 1 Vihara dan 50 pura. Terakhir 46 unit pasar tradisional rusak, 566 Kios dan toko rusak, Hotel sebanyak 138 unit rusak. Total kerusakan mencapai 10,1 Triliun dan total kerugian sebesar 8,6 Triliun (Tempo.co, 10 September 2018).

Gempa bumi dan tsunami yaitu dua dari sekian banyak bencana alam yang secara terus menerus terulang di daerah-daerah di Indonesia menimbulkan kerugian materi, korban jiwa dan taruma yang berkepanjangan. Berdasarkan kenyataan itulah harus ada upaya preventif semua pihak yang dilakukan untuk mengurangi risiko dan dampak kerugian yang ditimbulakannya dengan manajemen mitigasi bencana sejak dini di satuan pendidikan.

\section{PERNYATAAN MASALAH}

Memahami dan menyadari pola dan mekanisme gempa bumi dan tsunami di beberapa wilayah di Indonesia khususnya di daerah Lombok sebagai pola mekanisme siklus yang berpotensi terus terulang kembali pada kurun waktu telah dan masa tertentu, hal itulah menjadi pertimbangan pentingnya mitigasi bencana dengan manajemen kebencanaan yang baik dalam mengurangi risiko dan dampak yang ditimbulkan pada masa mendatang. Upaya dini yang paling efektif dapat dilakukan adalah dengan melakukan pendidikan kebencanaan sejak dini bagi satuan PAUD, yang dirumuskan dalam pentanyaan berikut.

1. Bagaiaman manajemen kebencanaan yang efktif?

2. Apa pendekatan pendidikan kebencanaan sejak dini disatuan PAUD?

\section{TUJUAN}

Berdasarkan penyataan rumusan masalah itulah, maka penetapan tujuan studi ini adalah untuk:

1. Mendeskripsikan mitigasi kebencanaan yang efektif dengan manajemen yang baik.

2. Memilih dan mendeskripsikan pendekatan pendidikan kebencanaan bagi satuan PAUD. 


\section{LITERATUR}

\section{Manajemen Mitigasi Bencana}

Manajemen adalah ilmu dan seni yang mengatur proses pemanfaatan sumber daya manusia secara efektif, dengan didukung oleh sumber-sumber lainnya dalam suatu organisasi untuk mencapai tujuan (Athoillah, 2010:14). Prihantoro (2012:40) memaknai manajemen sebagai siklus proses melakukan perencanaan, pengorganisasian, pengarahan dan pengendalian penggunaan sumber daya untuk mencapai tujuan dan sasaran kinerja. Sutikno (2012:4) menyimpulkan bahwa manajemen adalah serangkaian kegiatan merencanakan, mengorganisasikan, memotivasi, mengendalikan, dan mengembangkan segala upaya didalam mengatur dan mendayagunakan sumber daya manusia, sarana dan prasarana untuk mencapai tujuan organisasi.

Keterangan dari para ahli tentang manajemen dapat ditarik kesimpulan bahwa manajemen adalah sekarangkaian upaya dalam memanfaatkan semua berdaya dengan cara terbaik untuk mencapai tujuan (goal) bersama..

Tujuan utama (ultimate goal) dari Mitigasi Bencana, yaitu: (1) mengurangi risiko atau mengelola risiko dan dampak yang ditimbulkan oleh bencana khususnya bagi penduduk, seperti korban jiwa (kematian), kerugian ekonomi (economy costs) dan kerusakan sumber daya alam; (2) sebagai landasan (pedoman) untuk perencanaan pembangunan; (3) meningkatkan pengetahuan masyarakat (public awareness) dalam menghadapi serta mengurangi dampak/risiko bencana, sehingga masyarakat dapat hidup dan bekerja dengan aman (wikipedia.org)

Tujuan mitigasi inilah menjadi pertimbangan dalam menyusun program mitigasi khususnya di wilayah Indonesia yang termasuk wilayah rawan bencana, yaitu dengan; (1) mitigasi bencana harus diintegrasikan dengan proses pembangunan; (2) fokus bukan hanya dalam mitigasi bencana tetapi juga pendidikan, pangan, tenaga kerja, perumahan dan kebutuhan dasar lainnya; (3) sinkron terhadap kondisi sosial, budaya serta ekonomi setempat; (4) dalam sektor informal, ditekankan bagaimana meningkatkan kapasitas masyarakat untuk membuat keputusan, menolong diri sendiri dan membangun sendiri; (5) menggunakan sumber daya dan daya lokal (sesuai prinsip desentralisasi); (6) mempelajari pengembangan konstruksi rumah yang aman bagi golongan masyarakat kurang mampu, dan pilihan subsidi biaya tambahan membangun rumah; (7) mempelajari teknik merombak (pola dan struktur) pemukiman; (8) Mempelajari tata guna lahan untuk melindungi masyarakat yang tinggal di daerah yang rentan bencana dan kerugian, baik secara sosial, ekonomi, maupun implikasi politik (9) Mudah dimengerti dan diikuti oleh masyaraka (Wikipedia.org)

Berdasarkan latar belakang wilayah Indonesia yang rawan terjadi bencana gempa bumi itulah yang mengharuskan Indonesia memiliki manajemen bencana yang baik guna mengawasi dan menanggulangi bencana sebelum, ketika dan pasca gempa bumi. Menurut Undang-undang Nomor 24 Tahun 2007 tentang Penanggulangan Bencana, manajemen bencana memiliki tiga jenis, yaitu pendekatan mitigasi bencana, kebijakan dan strategi mitigasi bencana.

\section{Pendidikan mitigasi bencana bagi anak usia dini pada PAUD}

Mengenang dahsyatnya gempa bumi Lombok tahun 2018 lalu yang tidak hanya menimbulkan kerusakan bangunan rumah warga, fasilitas sekolah, rumah sakit, tempat ibadah, dan fasilitas umum lainnya, juga telah menelan ratusan korban jiwa, ribuan luka-luka dan ratusan ribu warga mengungsi. Ditambah lagi gempa 
susulan yang menimbulkan kepanikan dan trauma yang berkepanjangan, hal ini membuat aktivitas belajar-mengajar pada semua jalur dan jenjang pendidikan tidak dapat berlangsung normal, bahkan banyak sekolah yang terpaksa meliburkan peserta didiknya untuk menghindari risiko dan dampak gempa susulan yang berlangsung hampir 3 bulan.

Pentingnya memberikan pendidikan mitigasi bagi anak usia dini pada satuan pendidikan anak usia dini pada jalur pendidikan formal yang menyelenggarakan program pendidikan bagi anak berusia 4 (empat) tahun sampai dengan 6 (enam) tahun berdasarkan Peraturan Pemerintah Republik Indonesia Nomor 66 Tahun 2010 yang disebut Taman Kanak-Kanak (TK). Anak didik di TK termasuk dalam usia emas perkembangan, pada rentang usia 4 sampai dengan 6 tahun yang sejak lahir memiliki miliaran sel neuron yang harus terhubung dalam otaknya. Synopsis yang terjadi antar sel neuron pada masa golden age anak dapat mencapai perkembangan maksimal jika dilakukan sesuai dengan tahapan perkembangan secara berkesinambungan (Hariawan et al., 2019). Stimulus yang dilakukan melalui proses pengalaman belajar sambil bermain ini menjadi momen yang berharga untuk menanamkan pemahaman tentang mitigasi bencana sejak dini, maka memilih dan menentukan strategi pendidikan anak usia dini dapat mempermudah penyampaian informasi kepada peserta, sebagaimana yang disampaikan Nuraeni (2014) bahwa strategi pendidikan anak usia dini dapat dilakukan secara bersama-sama lingkungan sekolah, lingkungan keluarga, dan lingkungan masyarkat.

\section{METODE}

Penelitian ini mengunakan metode kualitatif dengan rancangan studi literatur dari berbagai sumber di artikel jurnal dan pristiwa yang terekam dan tersedia dalam media cetak dan online. Selanjutnya analisis data menggunakan model intraktif dari Miles and Huberman (2014), meliputi, pengumpulan data, verifikasi, kondesnsasi, dan kesimpulan temuan.

\section{HASIL DAN PEMBAHASAN}

Hasil studi literature tentang manajemen mitigasi bencana pada satuan pendidikan anak usia untuk pengurangan risiko bencana gempa bumi dan tsunami, sesuai dengan tujuan penelitian, yaitu: (1) Manajemen mitigasi bencana yang baik, meliputi; menetapkan pendekatan mitigasi bencanam, menetapkan kebijakan mitigasi bencana, menetapkan strategi mitigasi bencana, mitigasi bencana gempa bumi dan tsunami; dan (2) Pendidikan kebencanaan di satuan PAUD dengan pendekatan pembelajaran model PURINA, secara berurutan dibahas sebagai berikut.

\section{Manajemen Mitigasi Bencana}

1. Menetapkan pendekatan mitigasi bencana

Pendekatan mitigasi bencana dilakukan dengan dua cara, yaitu: (1) pendekatan struktural merupakan upaya mitigasi bencana melalui pembangunan prasarana fisik dan pemanfaatan teknologi. Dengan kata lain, rekayasa ketahanan bangunan akan bencana. Contohnya adalah adanya alat pendeteksi aktivitas gunung. Semua proses koordinasi dan pengambilan kebijakan dilakukan secara terpimpin, sama halnya seperti warga di Fiji Jepang saat terkena bencana alam tsunami, memberikan pembelajaran sosial bagi masyarakat dalam pengambilan keputusan saat menghadapi bencana (Takasaki, 2016); dan (2) pendekatan non-struktural 
merupakan upaya mitigasi bencana melalui pembuatan kebijakan atau peraturan tertentu.

Dengan kata lain, pendekatan yang dilakukan terhadap kesadaran manusia. Contohnya adalah Undang-undang Penanggulangan Bencana. (Dema 2020). Pendekatan non-struktural dapat juga dilakukan dengan kegiatan partisipasi dari masyarakat dalam menghadapi bencana, dipercaya memiliki pengaruh positif dalam mitigasi bencana. Hal ini serupa dengan masyarakat di Phang Nga, Thailand yang daerahnya menjadi titik rawan Tsunami (Witvorapong et al., n.d.).

\section{Menetapkan kebijakan mitigasi bencana}

Berbagai prinsip yang diperlukan dalam upaya mitigasi bencana yaitu: (a) memahami bahwa bencana dapat diprediksi secara alamiah dan saling berkaitan antara satu dengan bencana lainnya sehingga perlu di evaluasi terus menerus; (b) upaya mitigasi bencana harus memiliki persepsi yang sama baik dari aparat pemerintahan ataupun masyarakatnya, salah satunya dahulukan kelompok rentan; (c) upaya preventif harus diutamakan untuk mengurangi dampak bencana, dan (d) upaya mitigasi bencana terkoordinir secara terpadu bagi aparat ataupun masyarakatnya

3. Menetapkan strategi mitigasi bencana

Adapun strategi agar upaya mitigasi bencana dapat terkoordinir dengan baik adalah sebagai berikut.

a. Pemetaan menjadi hal terpenting dalam mitigasi bencana, khususnya bagi wilayah yang rawan bencana. Hal ini dikarenakan sebagai acuan dalam membentuk keputusan antisipasi kejadian bencana. Pemetaan akan tata ruang wilayah juga diperlukan agar tidak memicu gejala bencana. Sayangnya, untuk kasus di Indonesia pemetaan tata ruang dan rawan bencana belum terintegrasi dengan baik.

b. Pemantauan, hasil pemetaan tingkat kerawanan bencana akan setiap daerah sangat membantu dalam pemantauan dari segi prediksi terjadinya bencana. Hal ini akan memudahkan upaya penyelamatan apabila terjadi bencana. Pemantauan juga dapat dilakukan untuk pembangunan infrastruktur agar tetap memperhatikan AMDAL.

c. Penyebaran informasi dapat dilakukan ke media cetak ataupun elektronik. Informasi ini berupa cara mengenali gejala bencana, pencegahan, dan penanganan apabila terjadinya bencana. Hal ini dapat meningkatkan rasa kewaspadaan akan bencana.

d. Sosialisasi, Penyuluhan, dan Pendidikan. Beberapa masyarakat mungkin ada yang tidak dapat mengakses informasi mengenai bencana. Oleh karena itu, tugasnya aparat pemerintahan untuk melakukan sosialisasi ke masyarakat. Adapun bahan penyuluhan sama seperti di penyebaran informasi. Selain itu, mitigasi bencana juga turut diikutsertakan dalam kurikulum pendidikan anakanak.

4. Penerapan mitigasi bencana gempa bumi dan tsunami

Bencana gempa bumi selain mengakibatkan kerusakan dan korban jiwa pada permukaan lempeng bumi, juga dapat berpotensi tsunami jika epicentre kekuatan gempa dengan magnitudo di atas 7 Skala Richter. Oleh karena langkah-langkah penanganan pengurangan risiko dilakukan sebagai berikut.

Pertama upaya pengurangan bencana gempa bumi, antara lain, yaitu: (1) memastikan bangunan harus dibangun dengan konstruksi tahan getaran/gempa; (2) 
memastikan kekuatan bangunan dengan mengikuti standard kualitas bangunan; (3) pembangunan fasilitas umum dengan standard kualitas yang tinggi; (4) memastikan kekuatan bangunan-bangunan vital yang telah ada; (5) rencanakan penempatan pemukiman untuk mengurangi tingkat kepadatan hunian di daerah rawan bencana. Kedua upaya pengurangan bencana tsunami, antara lain: (1) peningkatan kewaspadaan dan kesiapsiagaan terhadap bahaya tsunami; (2) pendidikan kepada masyarakat tentang karakteristik dan pengenalan bahaya tsunami; (3) pembangunan tsunami early warning system; (4) pembangunan tembok penahan tsunami pada garis pantai yang berisiko; (5) penanaman mangrove serta tanaman lainnya sepanjang garis pantai meredam gaya air tsunami; (6) pembangunan tempat-tempat evakuasi yang aman di sekitar daerah pemukiman. Tempat/bangunan ini harus cukup tinggi dan mudah diakses untuk menghindari ketinggian tsunami

\section{Pendidikan Kebencanaan di satuan PAUD}

Pendidikan mitigasi bencana Gempa Bumi bagi anak usia dini dapat dilakukan sesuai dengan jenis bencana yang dihadapi sebagai upaya mengurangi risiko bencana pada anak usia dini dengan menggunakan Bahan Ajar Pendidikan Pengurangan Risiko Bencana (Model PURINA) dari Tim Pengembangan Pendidikan Anak Usia Dini dan Pendidikan Masyarakat Sulawesi Selatan, Kementerian Pendidikan dan Kebudayaan Republik Indonesia (Tim, 2019).

Pendekatan pembelajaran tentang mitigasi bencana gempa bumi bagi anak usia dini menggunakan Model PURINA (Tim, 2019), dengan tahapan sebagai berikut:

1. Mengenalkan lempengan permukaan bumi bagaikan lempengan puzzle (Gambar 2)

Mengenalkan kepada anak bahwa tempat ditinggali ini memiliki permukaan lempeng bumi seperti puzzle. Ada sekitar 20 puzzle (lempengan yang terus bergerak) dan yang dapat menimbulkan getaran pada permukaan lempeng bumi yang disebut sebagai gempa bumi

2. Mengenalkan gempa bumi itu terjadi karena getaran lempengan permukaan bumi (Gambar 3)

Mengenalkan tentang gempa bumi adalah getaran yang terjadi di permukaan bumi karena adanya gerakan lempeng bumi dengan menggunakan gambar karakter yang mudah dimengerti oleh anak usia dini. Dengan mengenal getaran permukaan lempengan bumi sebagai gempa bumi, kemudian anak diajari cara menyelamatkan diri ketika anak dihadapkan dengan kondisi tersebut, yaitu dengan cara mencari tempat perlindungan sebagaimana dapat dilihat pada Gambar 4

3. Mengajarkan anak cara berlindung dari bencana gempa bumi terjadi (Gambar 4)

Mengajari anak untuk mencari tempat-tempat berlindung terdekat di sekitarnya ketika gempa bumi terjadi, misalnya dengan berlindung di bawah meja yang masih cukup kuat, dan menjauhi kaca jendela dan lemari

4. Menjauhi kaca lemari dan jendela (Gambar 5)

Ketika terjadi gempa agar menjauhi jendela kaca dan lemari kaca yang mudah pecah akibat getaran yang diakibatkan oleh gempa bumi, dan menjauhi barangbarang lainnya yang mudah pecah.

5. Bersikap tenang dan tidak panik (Gambar 6) 
Ketika gempa bumi terjadi berupaya untuk tenang dan tidak panik dengan tetap memperhatikan lingkungan sekitar dan mencari tempat lapang yang lebih aman.

6. Menggunakan tangga darurat (Gambar 7)

Ketika sedang berada dalam gedung mengupayakan untuk tidak turun melalui lift dan segera menuju titik kumpul dengan menggunakan tangga darurat sambil tetap memperhatikan keselamatan diri.

7. Melindungi kepala dengan kedua tangan (Gambar 8)

Ketika terjadi gempa berupaya melindungi bagian tubuh seperti kepala dari reruntuhan dengan peralatan yang ada atau setidaknya dengan menggunakan kedua tangan sendiri.

8. Menjauhi gedung bertingkat atau tiang yang mudah tumbang (Gambar 9)

Menjauhi dan tidak mendekati gedung bertingkat atau tiang yang mudah tumbang karena akan membahayakan diri.

9. Menuju titik kumpul (Gambar 10)

Segera mungkin mencari tempat sekitar yang paling dan titik kumpul yang diarahkan oleh petugas yang berwenang, serta selalu berdoa agar senantiasa diberikan keselamatan dari musibah yang dihadapi.

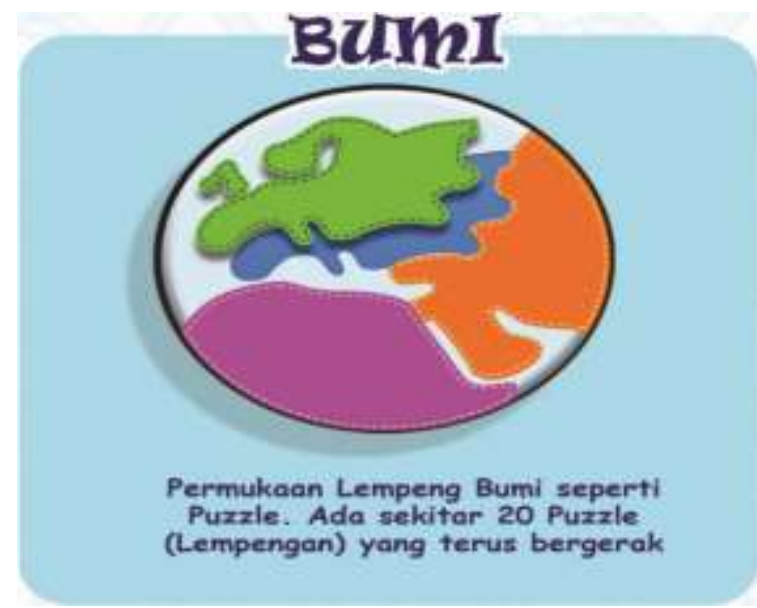

Gambar 2. Mengenal Lempengan Bumi Sumber: Model Purina (Tim, 2019)

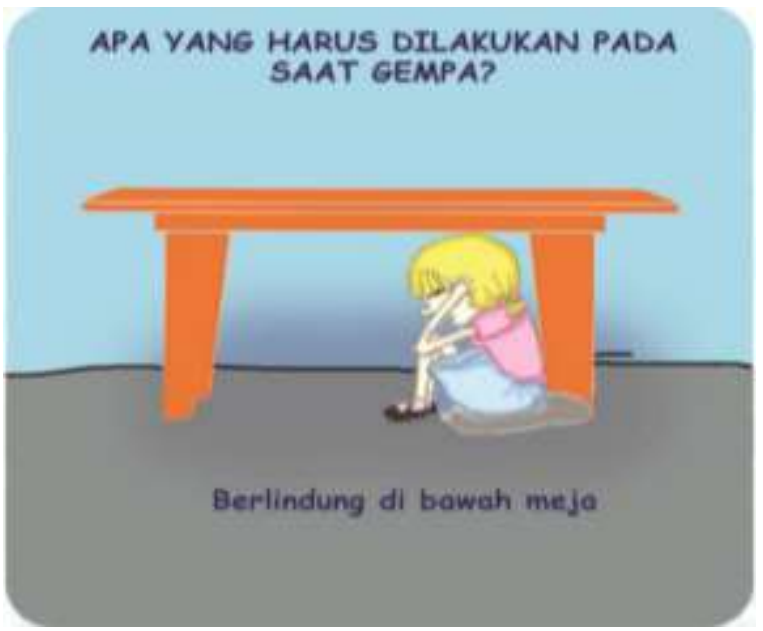

Gambar 4. Berlindung dibawah meja Sumber: Model Purina (Tim, 2019
GEMPA BUMMI

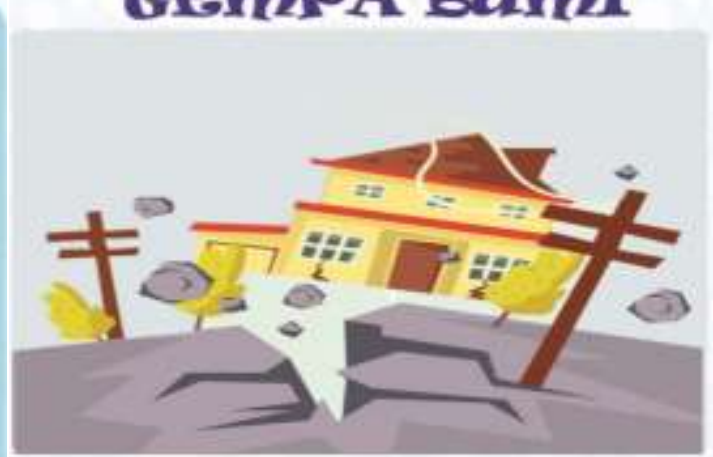

Gempa Bumi adalah getaran yang terjadi dipermukaan Bumi karena adamya gerakan Lempeng Bumi.

Gambar 3. Karakter Gempa Bumi Sumber: Model Purina (Tim, 2019)

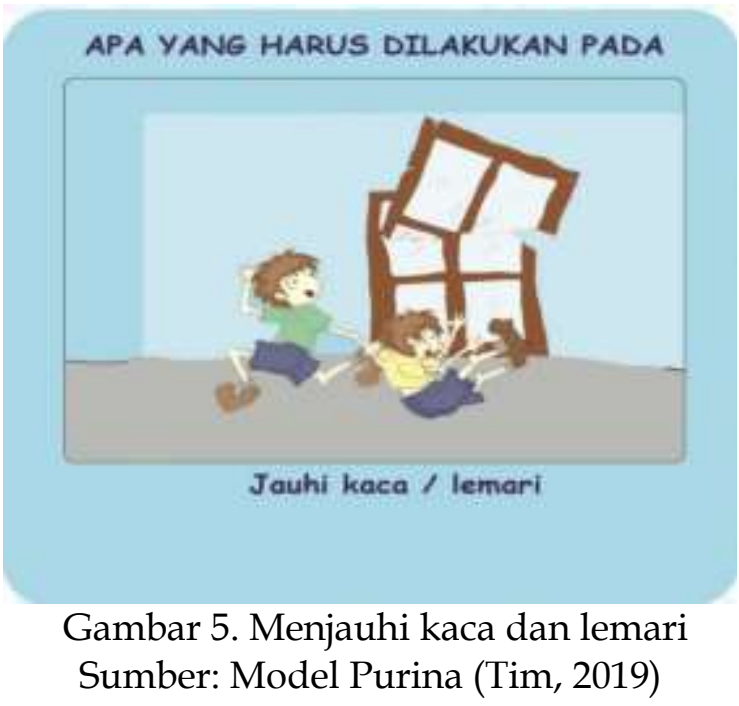




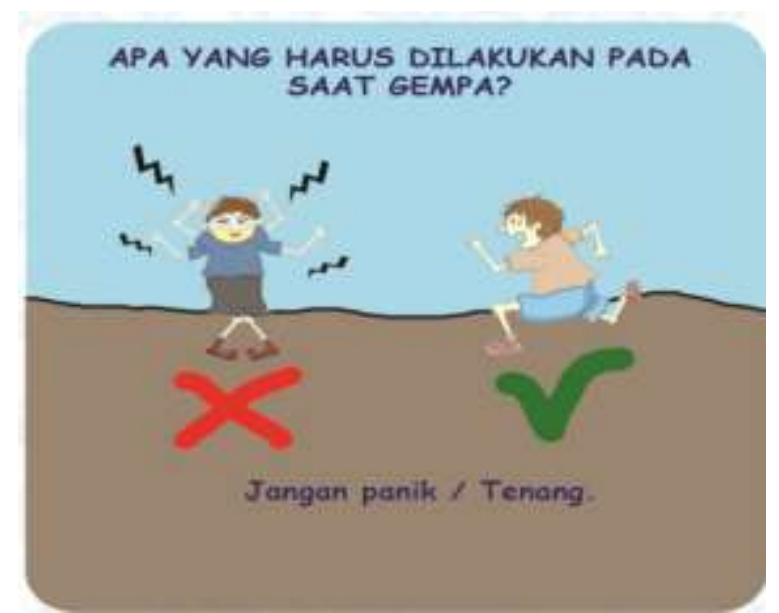

Gambar 6. Bersikap Tenang

Sumber: Model Purina (Tim, 2019

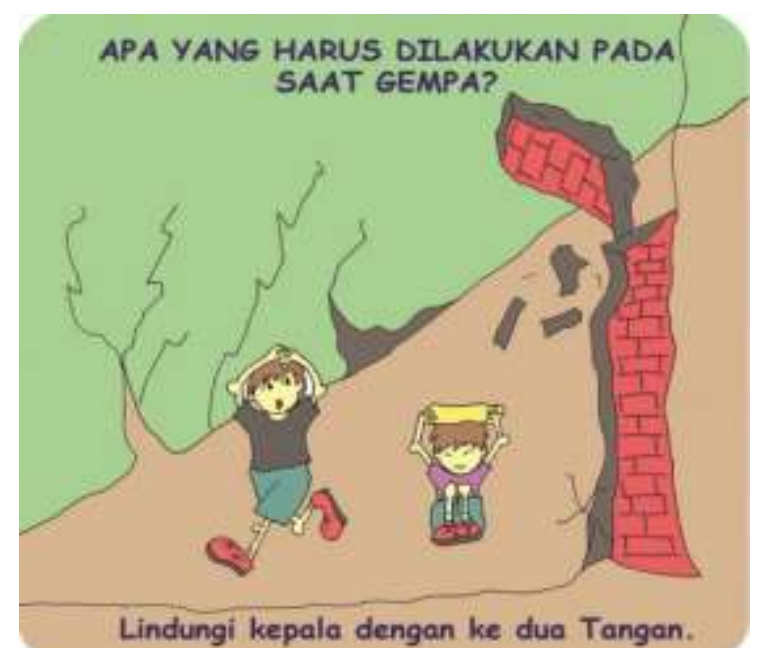

Gambar 8. Melindungi Kepala

Sumber: Model Purina (Tim, 2019

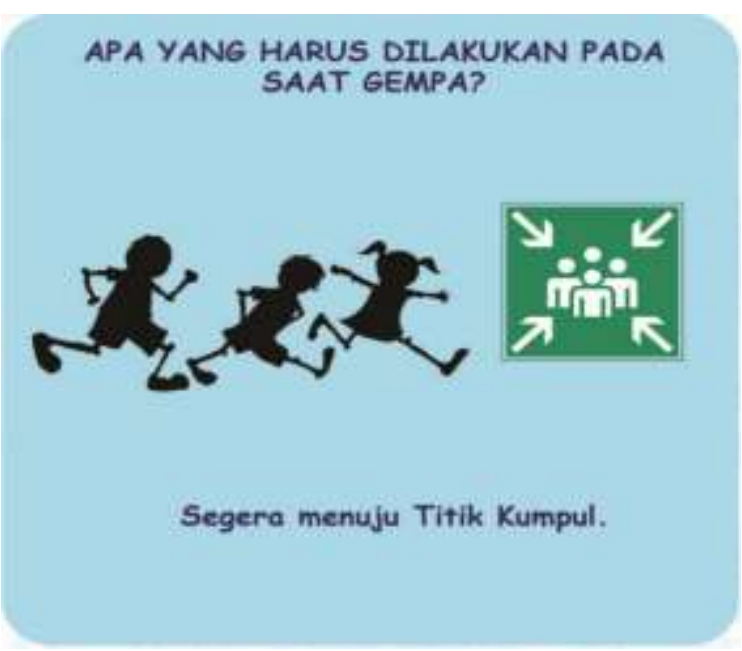

Gambar 10. Menuju titik kumpul Sumber: Model Purina (Tim, 2019
APA YANG HARUS DILAKUKAN PADA SAAT GEMPA?
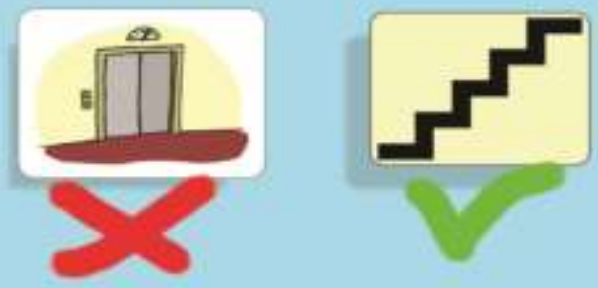

Jika berada di dalam gedung. Jangan menggunakan lift, tapi pakai tangga darurat menuju tempat terbuka atau titik kumpul.

Gambar 7. Menggunakan tangga darurat Sumber: Model Purina (Tim, 2019

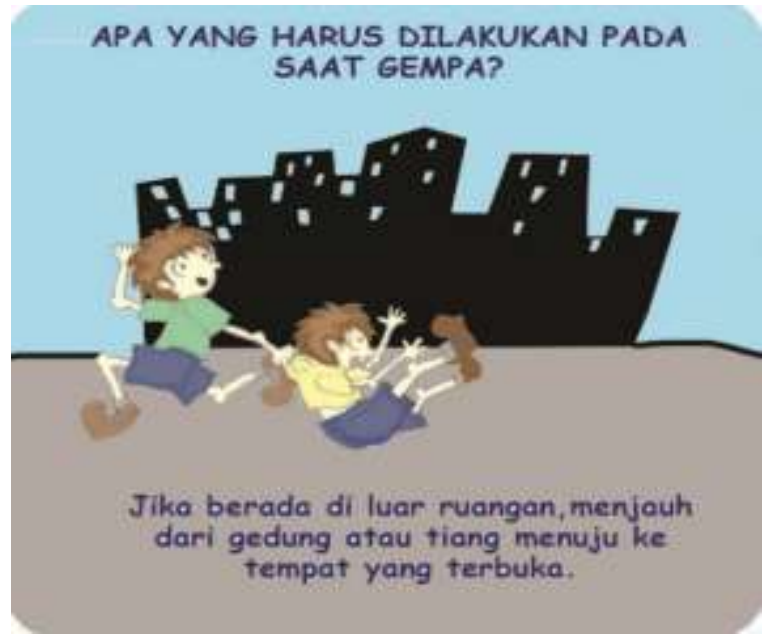

Gambar 9. Menjauhi Gedung Tinggi

Sumber: Model Purina (Tim, 2019

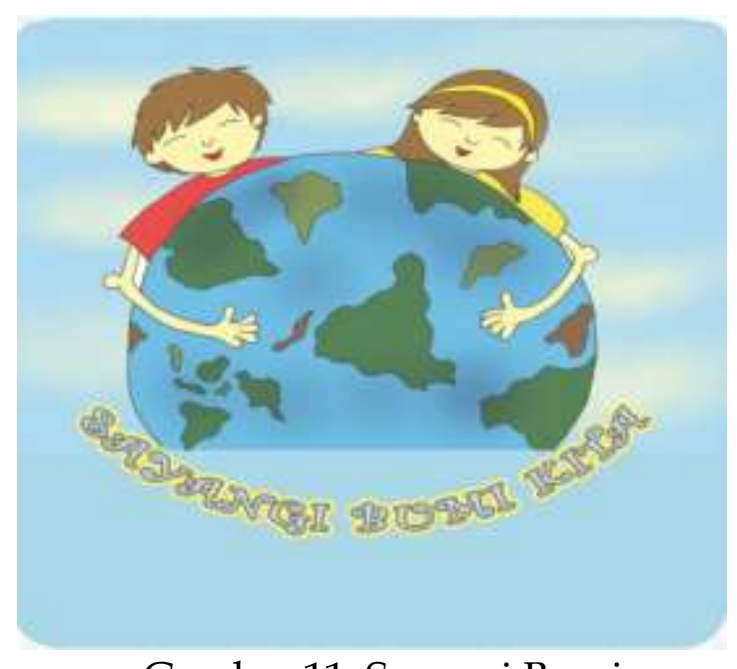

Gambar 11. Sayangi Bumi

Sumber: Model Purina (Tim, 2019 
Penanaman tentang mitigasi bencana dirasa sangat penting dilakukan sejak usia dini, agar memiliki ketahanan diri yang tangguh. Bahan Ajar model PURINA dianggap sebagai salah satu pendekatan pendidikan mitigasi bencana yang sangat tepat untuk mengurangi risiko bencana yang dapat ditimbulkan oleh gempa bumi dengan menggunakan gambar karakter untuk mempermudah anak didik dalam memahami tentang bencana serta mampu mengambil tindakan yang tepat dalam melindungi dirinya, ketika bencana itu terjadi.

\section{KESIMPULAN}

Manajemen mitigasi bencana yang baik, meliputi; menetapkan pendekatan mitigasi bencana baik secara struktural dan non-struktural, menetapkan kebijakan mitigasi bencana dengan pembagian tanggung jawab yang jelas, menetapkan strategi mitigasi bencana yang efektif, melakukan mitigasi bencana gempa bumi dan tsunami yang efektif kesiap-siagaan sebelum bencana, penanganan ketika bencana dan pemuliohan (recovery) pasca bencana.

Program mitigasi bencana dapat dilakukan melalui kegiatan penyuluhan ke masyarakat, melalui program pendidikan sejak dini di satuan PAUD. Pendidikan mitigasi bencana bagi anak usia dini harus dilakukan dengan pendekatan pembelajaran yang tepat, salah satunya adalah pendekatan model PURINA yang dikembangkan oleh Tim dari Balai Pengembangan Pendidikan Anak Usia Dini dan Pendidikan Masyarakat, Kementerian Pendidikan dan Kebudayaan Republik Indonesia. Model PURINA dianggap sebagai salah satu pendekatan pendidikan kebencanaan yang paling tepat untuk saat ini, kerena sangat mudah difahami bagi anak usia dini. Disain gambar, dan karakter yang ditampilkan menimbulkan rasa ingin tahu anak untuk terus belajar.

\section{SARAN}

Manajemen mitigasi bencana sebaiknya dapat dilakukan melalui program pendidikan pada satuan pendidikan anak usia dini. agar mereka nantinya telah memiliki ketahanan diri yang tangguh dan memiliki recovery self lebih cepat. Diperlukan pengembangan model kurikulum pembelajaran kebencanaan sesuai dengan kebutuhan perkembangan anak usia dini.

\section{UCAPAN TERIMAKASIH}

Penelitian ini tidak menerima hibah khusus dari agensi pendanaan mana pun di sektor publik, komersial, atau nirlaba.

\section{DAFTAR PUSTAKA}

Amalia, D. (2020). Mitigasi Bencana. Online: (https://www.studiobelajar.com/mitigasi-bencana/), diakses sabtu, 7 Maret 2020 pukul $10.00 \mathrm{WIB}$

Athoillah, A. (2010). Dasar-Dasar Manajemen. Bandung: Pustaka Setia

Literasipublik.com (https://www.literasipublik.com/wilayah-indonesia-rawanbencana), diakses, Jumat, 6 Maret 2020 pukul 08.30 WIB.

McCaffrey, R., \& Nabelek, J. (1987). Earthquakes, gravity, and the origin of the Bali Basin: An example of a Nascent Continental Fold-and-Thrust Belt. Journal of Geophysical Research, 92(B1), 441. https:// doi.org/10.1029/JB092iB01p00441 
Miles, M. B., Huberman, M. A., \& Saldana, J. (2014). Qualitative Data Analysis (3rd ed.). California: SAGE Publication, Inc

Mujiburrahman, M., Masjudin, M., Irawan, D., Zaenudin, M., Septiana, W., Suhaini, S., \& Irwansyah, I. (2019). KKN KBM Berbasis Masjid Sebagai Model Trauma Healing Berkelanjutan Pasca Gempa di Lombok Utara. Sasambo: Jurnal Abdimas (Journal of Community Service), 1(1), 36-44. https://doi.org/10.36312/sasambo.v1i1.122

Nuraeni, N. (2014). STRATEGI PEMBELAJARAN UNTUK ANAK USIA DINI. Prisma Sains: Jurnal Pengkajian Ilmu dan Pembelajaran Matematika dan IPA IKIP Mataram, 2(2), 143. https://doi.org/10.33394/j-ps.v2i2.1069

Nurjanah, Sugiharto R., Kuswanda Dede, BP Siswanto, Adikoesoemo. (2012). Manajemen Bencana. ALFABETA : Bandung.

Hariawan, R., Ulfatin, N., Huda A. Y., M., \& Arifin, I. (2019). Contributions Management of Parenting and Education Program to Strengthen the Service Three Early Childhood Education Center. International Education Studies, 12(2), 100. https:// doi.org/10.5539/ies.v12n2p100

Prihantoro, Rudy. (2012). Konsep Pengendalian Mutu. Bandung: Remaja Rosdakrya Sutikno, S. (2012). Manajemen Pendidikan. Lombok: Holistic

Sodikin, A. (2018). Melihat Kembali Gempa Lombok 2018 dan Sejarah Kegempaannya.

Online:

(https:/ / regional.kompas.com/read/2018/09/23/11321551/melihat-kembaligempa-lombok-2018-dan-sejarah-kegempaannya?page=all), diakses 6 Maret 2020, pukul 09.00 WIB.

Sonjaya, MRM. (2020). Manajemen Komunikasi Bencana Gempa Bumi Lombok Pada Masa Tanggap Darurat Di Lombok Nusa Tenggara Barat. Online: (http://eprints.ums.ac.id/80027/1/NASKAH\%20PUBLIKASI.pdf), diakses 6 Maret 2020

Takasaki, Y. (2016). Learning from disaster: Community-based marine protected areas in Fiji. Environment and Development Economics, 21(1), 53-77. doi:10.1017/S1355770X15000108

Tim. (2019). Bahan Ajar Pendidikan Pengurangan Risiko Bencana (Model PURINA). Balai Pengembangan Pendidikan Anak Usia Dini dan Pendidikan Masyarakat Sulawesi Selatan, Kementerian Pendidikan dan Kebudayaan Republik Indonesia.

Undang-undang Nomor 24 Tahun 2007 tentang Penanggulangan Bencana. Online: (https://bnpb.go.id/ppid/file/UU_24_2007.pdf) diakses

Witvorapong N, Muttarak R, Pothisiri W. (2015). Social Participation and Disaster Risk Reduction Behaviors in Tsunami Prone Areas. PLoS ONE 10(7): e0130862. https://doi.org/10.1371/journal.pone.0130862

Wikiepedia.org. Persiapan Online: (https://id.wikipedia.org/wiki/Persiapan_bencana), diakses 6 Maret 2020 pukul 09.15 WIB. 